
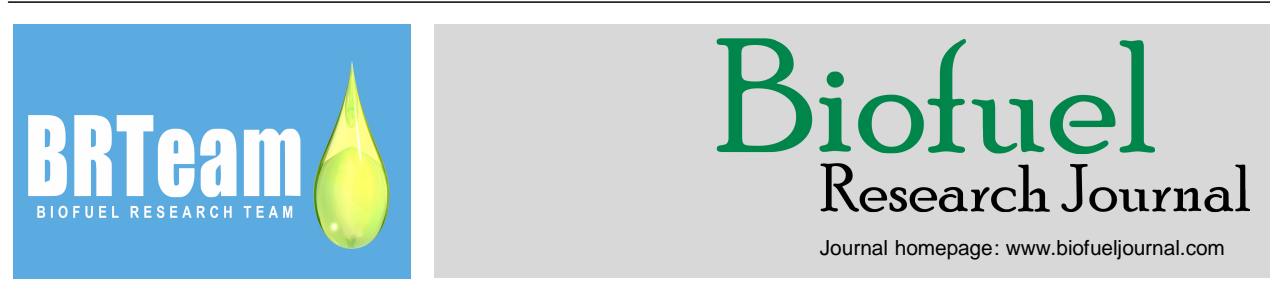

Original Research Paper

\title{
Optimization of biofuel production from corn stover under supply uncertainty in Ontario
}

Jonathan Ranisau ${ }^{1}$, Emmanuel Ogbe ${ }^{1}$, Aaron Trainor ${ }^{1}$, Mohammed Barbouti ${ }^{1}$, Mohamed Elsholkami ${ }^{1}$, Ali Elkamel ${ }^{1,2}$, Michael Fowler ${ }^{1, *}$

${ }^{1}$ Department of Chemical Engineering, University of Waterloo, Waterloo, Canada.

${ }^{2}$ Department of Chemical Engineering, Khalifa University, The Petroleum Institute, Abu Dhabi, UAE.

\section{HIGHLIGHTS}

$>$ Examined gasification of corn stover as means to convert waste biomass into fuel.

$>$ Biorefinery siting locations selected in Ontario counties.

$>$ MILP model accounts for corn stover supply uncertainty with stochastic programming. $>$ At least two biorefinery facilities are required to meet all province demands.

\section{GRAPHICAL ABSTRACT}
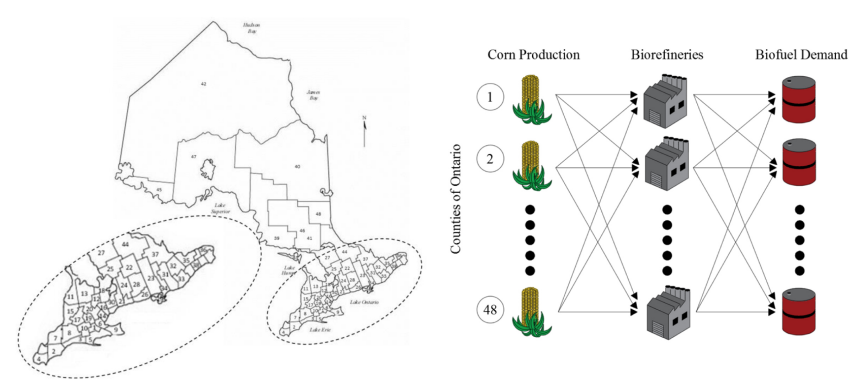

\section{ARTICLE INFO}

\section{Article history:}

Received 14 July 2017

Received in revised form 18 September 2017

Accepted 23 October 2017

Available online 1 December 2017

\section{Keywords:}

Biofuel

Supply chain optimization

Biomass to biofuels

Two-stage stochastic programming

Uncertainty

\begin{abstract}
In this paper, a biofuel production supply chain optimization framework is developed that can supply the fuel demand for $10 \%$ of Ontario. Different biomass conversion technologies are considered, such as pyrolysis and gasific ation and subsequent hydro processing and the Fischer-Tropsch process. A supply chain network approach is used for the modeling, which enables the optimization of both the biorefinery locations and the associated transportation networks. Gasification of corn stover is examined to convert waste biomass into valuable fuel. Biomass-derived fuel has several advantages over traditional fuels including substantial greenhouse gas reduction, generating higher quality synthetic fuels, providing a use for biomass waste, and potential for use without much change to existing infrastructure. The objective of this work is to show the feasibility of the use of corn stover as a biomass feedstock to a hydrocarbon biofuel supply chain in Ontario using a mixed-integer linear programming model while accounting for the uncertainty in the availability of corn stover. In the case study, the exact number of biorefineries is left as a policy decision and the optimization is carried out over a range of the possible numbers of facilities. The results obta ined from the case study suggests implementing gas ification technology followed by Fischer-Tropsch at two different sites in Ontario. The optimal solution satisfied $10 \%$ of the yearly fuel demand of Ontario with two production plants (14.8 billion L of fuel) a nd requires an investment of $\$ 42.9$ billion, with a payback period of about 3 years.
\end{abstract}




\begin{tabular}{|c|c|}
\hline \multirow{2}{*}{\multicolumn{2}{|c|}{ Sets/indices }} \\
\hline & \\
\hline$t$ & Set of biofuel demand sites \\
\hline$m$ & Set of biomass feedstock sites \\
\hline$r$ & Set of biorefinery sites \\
\hline$\Omega$ & Set of scenarios \\
\hline \multicolumn{2}{|l|}{ Parameters } \\
\hline$c_{b t}$ & Cost of biomass transportation \\
\hline$c_{p t}$ & Cost of biofuel transportation \\
\hline$c_{l t}$ & $\begin{array}{l}\text { Linearized cost of plant construction over range of } \\
\text { operation }\end{array}$ \\
\hline CONV & Biomass conversion to biofuel \\
\hline$d_{m, r}$ & $\begin{array}{l}\text { Distance from county with biomass feedstock ' } \mathrm{m} \text { ' to } \\
\text { biorefinery ' } \mathrm{r} \text { ' }\end{array}$ \\
\hline$d_{r, t}$ & $\begin{array}{l}\text { Distance from county with biorefinery ' } r \text { ' to biofuel } \\
\text { demand site ' } t \text { ' }\end{array}$ \\
\hline$F_{t}$ & Biofuel demand for site ' $\mathrm{t}$ ' \\
\hline$G_{m}$ & Biomass feedstock grown in site ' $\mathrm{m}$ ' \\
\hline$M$ & $\begin{array}{l}\text { Large value which helps accomplish the either-or } \\
\text { logical condition for biorefinery siting }\end{array}$ \\
\hline$N P$ & $\begin{array}{l}\text { Number of allowable plants to be constructed in the } \\
\text { province of Ontario }\end{array}$ \\
\hline \multicolumn{2}{|c|}{ Integer Variables } \\
\hline$W_{r}$ & $\begin{array}{l}\text { A binary variable equal to } 1 \text { if a biorefinery at } \\
\text { location ' } r \text { ' is chosen }\end{array}$ \\
\hline \multicolumn{2}{|c|}{ Continuous Variables } \\
\hline$U_{m, r}\left(U_{m, r, s}\right)$ & $\begin{array}{l}\text { Amount of biomass sent from location harvesting site } \\
\text { ' } \mathrm{m} \text { ' to biorefinery ' } \mathrm{r} \text { ' (for a scenario ' } \mathrm{s} \text { ') }\end{array}$ \\
\hline$V_{r, t}\left(V_{r, t, s}\right)$ & $\begin{array}{l}\text { Amount of biofuel sent from biorefinery 'r' to } \\
\text { demand site ' } d \text { ' (for a scenario 's') }\end{array}$ \\
\hline$Q_{r}\left(Q_{r, s}\right)$ & Production of biofuel at biorefinery ' $r$ ' (for a scenario s') \\
\hline
\end{tabular}

\section{Introduction}

Following the agreement at the $21^{\text {st }}$ Conference of the Parties in Paris, Canada has undertaken some of the most advanced climate change policies of the world. This is exemplified in the implementation of Canada's carbon tax of $\$ 50$ per tonne of carbon emission, beginning in 2022 (CNW, 2016). Current projections of Canada's transportation fuel usage to 2040 show increasing demands (NEB, 2016). Therefore, a more environmentally friendly method to produce fuels which can be used in existing transportation fuel networks is required for the country. Current fuel production methods are environmentally harmful and have had many cases of improper handling resulting in contamination (USEIA, 2017a). Additionally, the US Environmental Protection Agency has reported that $46 \%$ of the 2014 greenhouse gas emissions (GHG) for the United States was generated by the combustion of fossil fuels for electricity production and for transportation (NETL; Solomon et al., 2007). This means embarking on less carbon intensive technologies in Canada, the United States, and beyond should provide tremendous benefits for the environment.

Biomass is an organic material derived from plants and animals, and it is a renewable source of energy. Biomass contains stored energy which can be released as renewable electricity or heat when combusted, known as bioenergy. Alternatively, biomass can be converted into a liquid fuel called biofuel, which can be used as a substitute for petroleum fuels (USEIA, 2017b). The most common biofuels include bioethanol from corn, wheat or sugar beet and biodiesel from oil seeds (Demirbaş, 2001 and 2011). The liquid biofuels are used to run motor vehicles, and forest wood residue is used to run pulp mills and other industrial operations (Natural Resources Canada, 2016). Biofuels have the potential to be used with a limited change to existing infrastructure such as pipelines and pumping stations. In addition to this, renewable hydrocarbon biofuels offer many benefits, including engine and infrastructure compatibility, an abundance of a multitude of compatible biomass feedstocks otherwise wasted, environmentally friendly production processes, and higher quality of resulting synthetic fuels (AFDC, 2017).

For practical industrial scale applications, the biomass feedstock selection is set by a case-by-case basis. In general, the biomass suited for biofuel production has a relatively low growing time, high yield, easy processing, and abundance in the geographical location of interest (Natural Resources Canada, 2016). In the case of Ontario, corn is an abundant resource with high turn-over, but the supply chain is already heavily tied to the food and fuel industries (Marie-Andrée and Dorff, 2015). A key benefit of biofuels is that their life cycle carbon emissions are near zero, as the carbon released during combustion is captured with growing new energy crops. The stalks, leaves, and cobs that remain in the field after the corn harvest, is commonly referred to as corn stover. Corn stover is abundantly available with no current positive market value and thus is recommended for utilization in Ontario (Ebadian, 2015).

Biofuels can be classified based on their production technologies: firstgeneration biofuels; second generation biofuels; third generation biofuels; and fourth generation biofuels (Yue et al., 2014) and the focus of this work is on the 'second generation' biofuels. First-generation biofuels are made from the sugars which can be obtained from crops using conventional technology and are fully commercialized. On the other hand, second generation biofuels are made from lignocellulosic biomass, agricultural residues or waste woody mass of the crops. Several biomass conversion technologies have been proposed for 'second generation' biofuel production, but with only a few of these reaching the commercialization stage (Alternative Fuels Data Center, 2017). Amongst the existing techniques, two are most commonly used; fast pyrolysis followed by hydroprocessing and gasification followed by Fischer-Tropsch synthesis (Mochizuki et al., 2014; Wan et al., 2014). These techniques offer a high level of flexibility in terms of feedstock and products and thus provide economic feasibility (Anex et al., 2010; Leibbrandt et al., 2011).

Gasification and pyrolysis processes release abundant volatile components and minimal carbon dioxide by the conversion of carbonaceous feedstocks. Further, there is a low volume of flue gas associated with these alternative processes allowing for easier clean-up, resulting in a more economical production of high-quality synthetic gas (Rezaiyan et al., 2005). The main difference between gasification and pyrolysis processes is that gasification requires between one-fifth to onethird of the theoretical oxygen required for complete combustion, and is conducted at much higher temperatures. The oxygen present results in partial oxidation of gaseous fuels, producing the heat required for the gasification process (FAO, 1986). These result in elevated temperatures and higher quality syngas produced via the gasification process.

Furthermore, synthetic gas can be converted into synthetic fuels by hydroprocessing or via the Fischer-Tropsch reactions. In hydroprocessing, syngas is mixed with hydrogen at high pressures and temperatures to produce a bio-oil which can be distilled into hydrocarbon biofuels such as gasoline, diesel, and jet fuels. The Fischer-Tropsch process converts carbon monoxide and hydrogen to liquefied hydrocarbons, which can be distilled to produce products such as naphtha, kerosene, diesel, and paraffin wax (Rezaiyan et al., 2005). Since fast-pyrolysis occurs within a matter of seconds, there is significant importance in heat and mass transfer. Thus, to overcome complications with fast pyrolysis, and to produce higher quality synthetic gas, gasification followed by Fischer-Tropsch liquids production was selected as the optimal technology for this paper. In Figure 1, a schematic of the process is shown.

The hydrocarbon biofuel supply chain, is a form of the more general supply chain network problem, and can be modeled using a mixed integer linear programming (MILP) approach. Uncertainty is a major factor in the design of a reliable and robust supply chain network. Uncertainty may be introduced as seasonal and geographical fluctuations of biomass supplies, 
variability in biofuel demand, population growth, feedstock purchasing price, and hydrocarbon selling price (Rezaiyan et al., 2005). Additionally, uncertainties associated with process flowsheets for gasification and the Fischer-Tropsch process may be considered (Diwekar and Rubin, 1991; Acevedo and Pistikopoulos, 1998).

The goal of this work is to show the feasibility of the use of corn stover as a biomass feedstock to a hydrocarbon biofuel supply chain in Ontario using a MILP model while accounting for the uncertainty in the availability of corn stover. The structure of the paper is as follows: Section 2 presents some literature on biorefinery supply chains. Section 3 outlines the input data and model assumptions, and thereafter develops the deterministic and stochastic problem formulation. Section 4 presents results and discussion, and Section 5 outlines the conclusions.

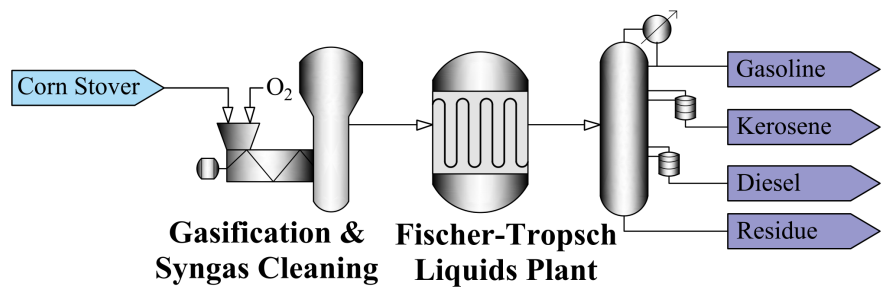

Fig.1. Gasification and Fischer-Tropsch Process Schematic.

\section{Literature review}

The research most relevant to the problem addressed is reviewed in this section. The synthesis and selection of biorefinery pathways, otherwise referred to as biomass to product supply chain, has been framed as an optimization problem with economic performance criteria (Čuček et al., 2010; Pham and ElHalwagi, 2012). Optimization techniques have been used to allocate products in a biorefinery (Sammons et al., 2008). However, equally important to the successful operation of a biorefinery is the siting and transportation scheduling (Grisi et al., 2011)

The deterministic model formulation of a biorefinery supply chain has been most often considered using MILP (Kim et al., 2011; Andersen et al., 2013). and mixed-integer nonlinear programming (MINLP) (Zamboni et al., 2009). MILP is a linear optimization technique used when the variables to be optimized are a mixture of integer variables (i.e., can only take on whole numbers, such as the number of biorefineries) and continuous variables (i.e., can take on real number values, such as production levels) (Hillier and Lieberman, 2000). The general formulation of an MILP is given as follows:

$$
\begin{array}{ll}
\min _{x, y} & \mathrm{c}_{1}^{T} x+\mathrm{c}_{2}^{\mathrm{T}} \mathrm{y} \\
\text { s.t. } & \mathrm{A}_{1} \mathrm{x}+\mathrm{A}_{2} \mathrm{y} \leq \mathrm{b} \\
& x \in X \subset \square_{\geq 0}, y \in \square^{n_{y}}
\end{array}
$$

where, $x$ is integer variable, $y$ is continuous variable, $C_{1}$ and $C_{2}$ are the costs associated with each unit increase of $x$ and $y$, respectively, $A_{l}$ and $A_{2}$ represent the technological matrix containing the coefficient of constraints in the optimization problem $(\mathbb{P})$.

Biofuel production or biorefinery supply chain MILP models include three main set of nodes (Simchi-Levi et al., 1999; Čuček et al., 2010; McLean et al., 2015): harvesting sites, biorefinery facilities, and retail centers. First, the harvesting sites consider production capacities and transportation scheduling between harvesting sites to biorefinery facilities. Second, the biorefineries facilities consider siting, technology selection, production levels of fuels, product mixes, biomass storage scheduling, and which biorefineries sites act as suppliers to retail centers. Third, the retail centers consider fuel sales (Andersen et al., 2013).

Different biorefinery technologies are available in the literature; either based on fast pyrolysis or gasification. In fast pyrolysis, biomass is exposed to high temperatures (usually about $500{ }^{\circ} \mathrm{C}$ ) at a high heating rate, in an inert atmosphere (Demirbaș, 2001; Demirbas, 2011; Wan and Wang, 2014). This method is deemed as the most economically feasible way to convert biomass into liquid fuels (Anex et al., 2010) superior to other thermochemical processes like liquefaction and gasification (Anex et al., 2010; Zhou et al., 2011). The different gasification types considered for biomass to biodiesel are; a high temperature, entrained flow gasifier (Van Bibber et al., 2007), a low temperature, fluidized bed gasifier (Bain, 1992; Larson et al., 2009), and a low temperature, indirectly heated gasifier (Dutta and Phillips, 2009).

Moreover, previous studies have contextualized their constraints by applying their model to a particular geographical location, such as Alabama and Illinois (Aksoy et al., 2011; Gebreslassie et al., 2012). In the context of a selected geography, the most suitable biomass for the location may be selected amongst agricultural residues, energy crops, and wood residues (Gebreslassie et al., 2012).

Additionally, the incorporation of uncertainties in parameters is handled in the modeling stage using stochastic programming. The most common technique to account for uncertainty is two-stage stochastic programming approach. The first-stage decisions in the two-stage programming formulation consist of capital investment decisions for size and location of biorefinery plants. The second-stage decisions are recourse decisions, such as production levels, etc. taken after uncertainties have been revealed.

In this paper, the agricultural residue known as corn stover is modeled as a feedstock to a biorefinery MILP supply chain implemented in the province of Ontario, Canada, while accounting for supply uncertainty and optimizing the number, location, and size of processing units and the amount of material to be transported (Kim et al., 2011).

\section{Modeling and optimization}

The study investigates the biorefinery supply chain shown in Figure 2. The superstructure depicts the network nodes representing the set of biomass feedstock harvesting sites indexed by $m$, biorefinery sites indexed by $r$, and biofuel demand sites with index $t$. The geographical areas of interest are the counties of Ontario. In this study, each county is a potential biomass feedstock harvesting site, a potential biorefinery site, and a biofuel demand site. The counties of Ontario with numbering convention used are summarized in Table 1.

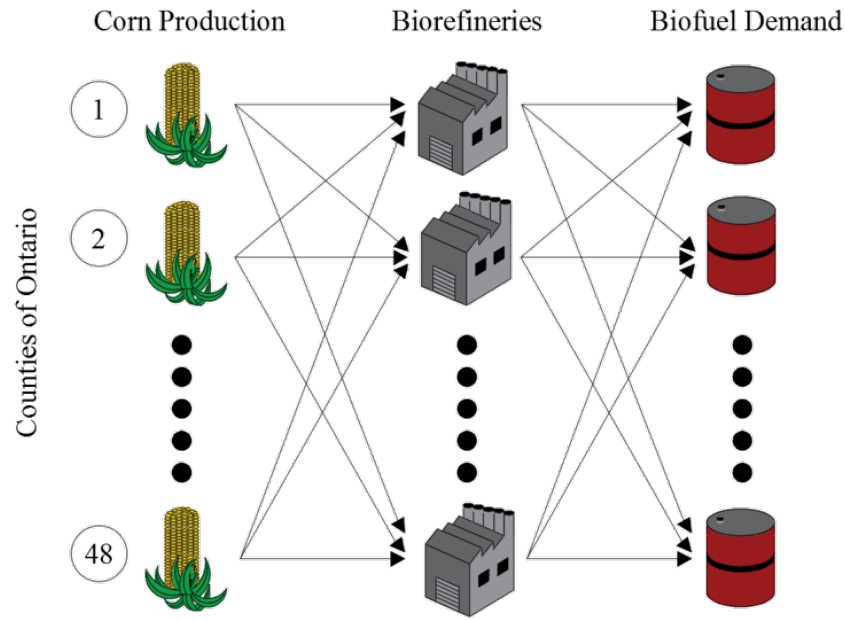

Fig.2. Superstructure for the Ontario biorefinery supply chain.

\subsection{Input data and model assumptions}

The map of the geographical locations of all the counties in Ontario considered is shown in Figure 3. For all cases, the corn production per county was retrieved from the Ontario Ministry of Agriculture, Food, and Rural Affairs (Provincial Field Crop Production and Prices, 2017).

Many processes for the gasification of corn stover were considered, such as low-temperature $\left(890^{\circ} \mathrm{C}\right)$, fluidized bed gasifier, a high-temperature $\left(1300^{\circ} \mathrm{C}\right)$, entrained flow gasifier, and gasification in supercritical water 
Table 1.

Ontario county names.

\begin{tabular}{llll}
\hline$\#$ & County & $\#$ & County \\
\hline $\mathbf{1}$ & Brant & $\mathbf{2 5}$ & Muskoka \\
$\mathbf{2}$ & Chatham-Kent & $\mathbf{2 6}$ & Northumberland \\
$\mathbf{3}$ & Elgin & $\mathbf{2 7}$ & Parry Sound \\
$\mathbf{4}$ & Essex & $\mathbf{2 8}$ & Peterborough \\
$\mathbf{5}$ & Haldimand-Norfolk & $\mathbf{2 9}$ & Prince Edward \\
$\mathbf{6}$ & Hamilton & $\mathbf{3 0}$ & York \\
$\mathbf{7}$ & Lambton & $\mathbf{3 1}$ & Frontenac \\
$\mathbf{8}$ & Middlesex & $\mathbf{3 2}$ & Lanark \\
$\mathbf{9}$ & Niagara & $\mathbf{3 3}$ & Leeds and Grenville \\
$\mathbf{1 0}$ & Oxford & $\mathbf{3 4}$ & Lennox and Addington \\
$\mathbf{1 1}$ & Bruce & $\mathbf{3 5}$ & Ottawa \\
$\mathbf{1 2}$ & Dufferin & $\mathbf{3 6}$ & Prescott and Russell \\
$\mathbf{1 3}$ & Grey & $\mathbf{3 7}$ & Renfrew \\
$\mathbf{1 4}$ & Halton & $\mathbf{3 8}$ & Stormont, Dundas and Glengarry \\
$\mathbf{1 5}$ & Huron & $\mathbf{3 9}$ & Algoma \\
$\mathbf{1 6}$ & Peel & $\mathbf{4 0}$ & Cochrane \\
$\mathbf{1 7}$ & Perth & $\mathbf{4 1}$ & Greater Sudbury \\
$\mathbf{1 8}$ & Simcoe & $\mathbf{4 2}$ & Kenora \\
$\mathbf{1 9}$ & Waterloo & $\mathbf{4 3}$ & Manitoulin \\
$\mathbf{2 0}$ & Wellington & $\mathbf{4 4}$ & Nipissing \\
$\mathbf{2 1}$ & Durham & $\mathbf{4 5}$ & Rainy River \\
$\mathbf{2 2}$ & Haliburton & $\mathbf{4 6}$ & Sudbury \\
$\mathbf{2 3}$ & Hastings & $\mathbf{4 7}$ & Thunder Bay \\
$\mathbf{2 4}$ & Kawartha Lakes & $\mathbf{4 8}$ & Timiskaming \\
\hline & & &
\end{tabular}

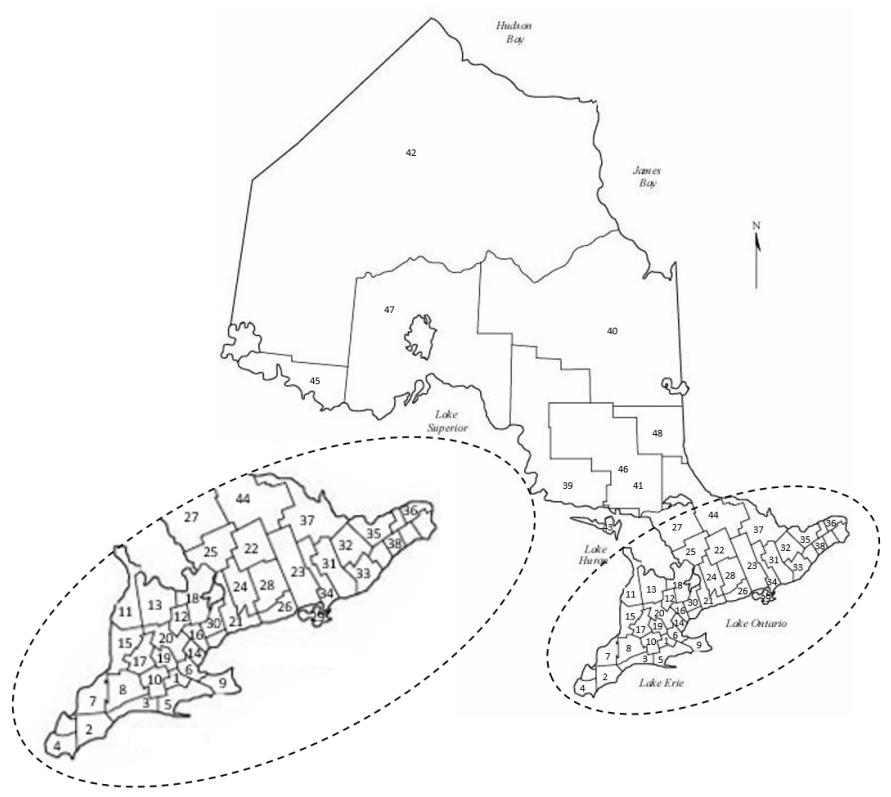

Fig.3. Map of Ontario counties.

(D'Jesús et al., 2006; Swanson et al., 2010). In this work, fluidized bed gasifier technology (followed by Fisher-Tropsch) was selected to produce a high-value biofuel asset, as many governments are requiring an increased concentration of renewable content in liquid fuels which will require an overall increase in production capacity. Based on economic and environmental considerations, the high-temperature, entrained flow gasifier was selected as the technology for this work. The capital cost estimation for the entrained flow gasifier is provided by Swanson et al. (2010). For the purposes of this work, a linear approximation of this cost function is used in the objective function. It is assumed that the capital cost will vary linearly to the size, and this assumption is an approximation. However, over the relatively narrow plant sizes used in this work, it is not expected to alter the results of the location and number of plants. The remaining assumptions for the model development are summarized as follows:
- $5 \%$ of the weight of corn is freely available as corn stover feedstock, and the product is biodiesel fuel.

- The technology selection for study is the high-temperature, entrained flow gasifier technology followed by Fisher-Tropsch for liquid fuel production (Swanson et al., 2010)

- The biofuel demand in each county is assumed based on $10 \%$ of the average fuel consumption per capita and the population of each county from the 2011 Census (Focus on Geography Series, 2011). Moreover, the shipping data was calculated based on distances between counties and transportation costs.

- A fixed cost is assumed per $\mathrm{km}$ per tonne of biomass transported and another fixed cost is assumed per $\mathrm{km}$ per L of gasoline transported. The distances are retrieved from Google's API (Google Maps APIs).

- A linear approximation of this cost function is used in the objective function.

The computational studies were performed on a ASUS-Notebook SKU with Intel ${ }^{\circledR}$ Core TM $15-3317 \mathrm{U}, 1.70 \mathrm{GHz}$ CPU and 4 GB RAM. The MILP model was coded in MATLABC 8.4 (version R2017a) and solved with the solver intlinprog and confirmed with IBM's commercial mathematical programming solver CPLEX.

\subsection{Deterministic formulation}

The deterministic model considers the location and operation of a biodiesel supply chain without consideration of uncertainty. This work develops in this section, the constraints for the optimization problem. The variables and parameters for this problem are listed in the Notations section. First, the biomass feedstock at each county $r$ necessary to generate biofuel $Q_{r}$ should be less than the biomass production in the county $G_{m}$ plus the net biomass sent/received to/from the counties $U_{m, r}$. Constraint 1 is written for each county and further requires that $m^{*}=r^{*}$ for the county which the constraint is being written.

$$
\begin{aligned}
& G_{m}+\sum_{m, r=r^{\prime}} U_{m, r}-\sum_{m=m^{*}, r} U_{m, r} \geq C O N V^{*} Q_{r} \\
& \forall m=m^{*}, r=r^{*}, m^{*}=r^{*} .
\end{aligned}
$$

Further, the biomass feedstock sent from each county $U_{m, r}$ cannot exceed the biomass feedstock supply $G_{m}$. Similar to Constraint 1 , Constraint 2 is written for each county and $m^{*}=r^{*}$ for the county which the constraint is being written

$$
\sum_{m=m^{*}, r} U_{m, r} \leq G_{m}, \forall m=m^{*}, m^{*}=r^{*}
$$

The biofuel demand $F_{t}$ at each county is met by the biofuel produced $Q$ in the county plus the net biofuel transportation $V_{r, t}$. Again, Constraint 3 is written for each county and further requires that $r^{*}=t^{*}$ for the county whose constraint is being written.

$$
\begin{aligned}
& G_{r}+\sum_{r, t=t^{*}} V_{r, t}-\sum_{r=r^{*}, t} V_{r, t}=F_{t}, \\
& \forall r=r^{*}, t=t^{*}, r^{*}=t^{*} .
\end{aligned}
$$

A policy decision was incorporated into the model to allow for the selection of the number of gasification and Fischer-Tropsch plants in the province of Ontario. The constraint was added using a binary variable or an either-or logical condition, $W_{r}$. If $W_{r}=1$, the production level is unconstrained, but if $W_{r}=0$, the production level is forced to zero. The parameter ' $M$ ' is a large value which accomplishes the logical condition. The conditional statement is defined in Constraint 4 and is repeated for each county. 
$Q_{r} \leq W_{r} * M, \forall r$

The policy decision is made by inputting the number of allowable plants $(N P)$ in Constraint 5.

$\sum_{r} W_{r} \leq N P$

The deterministic cost of operation is given in Constraint 6 .

$\operatorname{Cos} t^{\text {Det }}=c_{w l t} \sum_{r} W_{r}+c_{p l t} \sum_{r} Q_{r}+c_{t r n} \sum_{m} \sum_{r} d_{m, r} U_{m, r}+c_{t m} \sum_{r} \sum_{t} d_{r, t} V_{r, t}$

The deterministic model is given by the following:

$\min \operatorname{Cos} t^{\text {Det }}$

s.t. Constraints (1) to Constraints (6)

All the decision variables are required to be positive. Additional constraints added to Problem (Det) include the bounds placed on the decision variables as follows: $U_{m, r} \geq 0,0 \leq Q_{r} \leq 757.1, V_{r, t} \geq 0$ and $W_{r} \in \square$. An upper bound of $757.1 \times 10^{6} \mathrm{~L}$ per year of fuel produced at each gasification/Fischer-Tropsch plant is imposed based on capacities available in industry ( $S$ wanson et al., 2010).

\subsection{Stochastic formulation}

The mathematical formulation of the stochastic programming model is developed to allow the biomass transportation scheduling, biorefinery siting, biorefinery production levels and biofuel transportation scheduling while considering the uncertainty of the biomass supply. The classical two-stage stochastic programming (referred to as Problem (SP0) below) paradigm is adopted. The general form is as follows (Birge and Louveaux, 2011; Ogbe and Li, 2017),

$$
\begin{gathered}
\min _{x \in X \subset \square \geq 0} \mathrm{c}_{1}{ }^{\mathrm{T}} \mathrm{x}+\mathrm{E}_{\xi \in \Xi} Q(\mathrm{y}, \xi), \\
Q(x, \xi)=\min _{y} \mathrm{c}_{2}(\xi)^{\mathrm{T}} y \\
\text { s.t. } \mathrm{A}_{1} \mathrm{x}+\mathrm{A}_{2}(\xi) \mathrm{y} \leq \mathrm{b}(\xi), \\
\mathrm{y} \in \mathrm{Y}
\end{gathered}
$$

where $x$ are the first-stage variables, or 'here and now' decisions, that are made before the realization of uncertainty, and $y$ are the second-stage variables, or 'wait and see' decisions made after the uncertainty has been realized. The cost of making the second-stage decisions is $Q(y, \xi)$ given above, where $\xi \in \Xi$ , are the parameters that are not known with certainty when making the firststage decisions but becomes apparent when the second-stage decisions are made. A typical approach to solve Problem (SP) is to approximate the uncertainty set $\Xi$ by a finite subset $\hat{\Xi}$ that follow a discrete distribution with finite support $\hat{\Xi}=\left\{\xi_{1}, \ldots, \xi_{N_{s}}\right\} \subset \Xi$. Each realization (called scenarios) $s \in\left\{1, \ldots, N_{s}\right\} \in \Omega$, has an associated probability $p_{s}$, with $\sum_{s=1}^{N_{s}} p_{s}=1$. Discrete distributions have a lot of applications, either directly or empirically, as approximations to the underlying probability distribution. Problem (SP) is then the resulting two-stage scenario-based stochastic program:

$$
\begin{aligned}
& \min _{x, y_{1}, \ldots, y_{N_{s}}} \mathrm{c}_{1}^{\mathrm{T}} x+\sum_{s=1}^{N_{s}} \mathrm{c}_{2, s}{ }^{T} y_{s} \\
& \text { s.t. } \mathrm{A}_{1} \mathrm{x}+\mathrm{A}_{2, \mathrm{~s}} \mathrm{y}_{s} \leq \mathrm{b}_{s}, \quad \mathrm{~s}=1, \ldots, N_{s}, \\
& \quad \mathrm{x} \in X \subset \square_{\geq 0}, \mathrm{y}_{s} \in \square^{n_{y}}, \quad \mathrm{~s}=1, \ldots ., N_{s} .
\end{aligned}
$$

Note that Problem (SP) can be written in the form of (P) as explained in Ogbe and Li (2017). In the context of the biodiesel supply chain problem, the first-stage variables, $x$, are a set of integer variables to select a fixed number of plants $\left(W_{r}\right)$. The second-stage decision variables, $y_{s}$, are a set of continuous variables implemented after the realization of uncertainty, that is a combination of decisions relating to biomass feedstock transportation schedule $U_{m, r, s}$, biofuel production levels at each county $Q_{r, s}$, and biomass feedstock transportation schedule $V_{r, s}$. Notice that the variables $U_{m, r, s}, Q_{r, s}$ and $V_{r, d, s}$ correspond to the stochastic variants of $U_{m, r}, Q_{r}$ and $V_{r, t}$ respectively.

The model constraints are divided into first-stage and second-stage, as well. The first stage constraints are those constraints that do not contain second-stage scenario dependent variables. These are Constraints 4 and 5 shown in Section 3.2. The second-stage constraints incorporate uncertainty into the supply of biomass. They are Constraints 1-3. To avoid infeasibility of the inequality second-stage constraints, two slack variables $S U_{s}$ and $S L_{s}$ are defined to relax the inequality constraints in Constraints 1 and 2. In each scenario, a new value of biomass generation is selected from the historical distribution of biomass production. These two equations are modified into Constraints 7 and 8 as below.

$$
\begin{aligned}
& G_{m, s}+\sum_{m, r=r^{*}} U_{m, r, s}-\sum_{m=m^{*}, r} U_{m, r, s}+S U_{r, s}-S L_{r, s} \\
& =C O N V^{*} Q_{r, s}, \quad \forall m=m^{*}, r=r^{*}, m^{*}=r^{*}, s=1, \ldots, N_{s} .
\end{aligned}
$$

$\sum_{m=m^{*}, r} U_{m, r, s}+S U_{m, s}-S L_{m, s}=G_{m, s}$,

$\forall m=m^{*}, m^{*}=r^{*}, s=1, \ldots, N_{s}$.

The second-stage cost is given by the sum of the scenario probability and the second-stage cost. The probability of each scenario is assumed to be uniformly distributed. The slack variables are different for each constraint and scenario.

The total expected economic objective is given by Equation 1 .

$$
\operatorname{Cos} t^{s t o}=\operatorname{Cos} t 1^{s t o}+\operatorname{Cos} t 2^{s t o},
$$

where,

$$
\begin{aligned}
\operatorname{Cos} t 1^{s t o} & =c_{w l t} \sum_{r} W_{r}+c_{p t} \sum_{s=1}^{N_{s}} \sum_{r} d_{r, s} Q_{r, s} \\
& +c_{l t} \sum_{s=1}^{N_{s}} \sum_{m} \sum_{r} d_{m, r} U_{m, r, s}+c_{p t} \sum_{s=1}^{N_{s}} \sum_{r} \sum_{t} d_{r, t} V_{r, t, s} \\
\operatorname{Cos} t 2^{s t o} & =\sum_{s}^{N_{s}} \sum_{r} p_{s}\left(S U_{r^{*}, s}+S L_{r^{*}, s}\right)
\end{aligned}
$$

The two-stage stochastic programming model is given by the following: $\min \operatorname{Cos} t^{s t o}$

s.t. First stage Constraints (5),

Second stage Constraints (3)-(4),(7)-(8)

Problem (Sto) also includes the bound constraints imposed in the deterministic model, Problem (Det) in Section 3.2. 


\section{Results and discussion}

The analysis is separated into two studies: deterministic and stochastic. The deterministic study focuses on the impact of the policy decision of the number of gasification and Fischer-Tropsch plants to build and the overall costing allocation. The stochastic study assesses the uncertainty of corn stover supply on the results of the deterministic simulation. To do this, 5 scenarios of corn stover supply were considered in the study. For both cases, the number of gasification and Fischer-Tropsch plants is left as a policy decision by the province since unconsidered costs, such as administration costs required to organize the operation of the facilities, may be factored in by setting this variable. Furthermore, leaving this factor as a policy decision broadens the scope of this work, allowing for the examination and comparison of supply chains with various numbers of gasifiers.

In case one, the deterministic model was simulated for a policy decision ranging from $1-48$ (i.e., one for each region) conversion facilities using corn production data from 2016. In Figure 4, the results of the biorefinery siting are provided. The y-axis represents the policy decision of the number of plants to be implemented across Ontario. The blue dots represent the counties where the facilities should be located for each row of the selected policy decision. The dark orange line shows the sum of all selected counties for each policy decision row. For the constraints implemented in the model, the fewest number of gasifier facilities required to meet the fuel demand is two while the highest number of facilities is 48 .

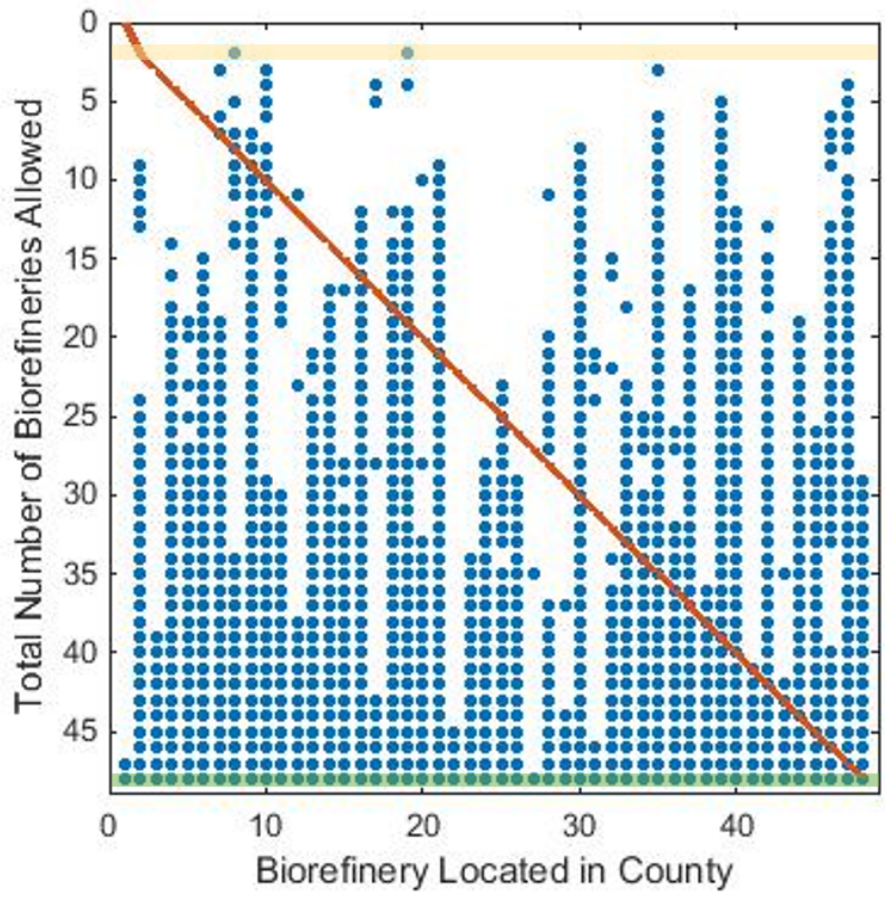

Fig.4. Deterministic biorefinery siting results.

The cost objective of the optimization causes optimal locations to change between different policy decisions for the number of facilities. For example, Lambton, a highly industrial district with many existing chemical facilities, is chosen as a site when the policy decision is set to fifteen or higher, but not selected when the policy decision is set to fourteen or lower. The three most reoccurring districts across all the policy decisions are: Algoma, Ottawa, and Thunder Bay. In contrast, if the policy decision is set to the minimum of two, the optimal locations to construct the biorefineries are: Waterloo and Middlesex. These results are summarized in Figure 5.

A cost breakdown of the solution shows that over $99 \%$ of the cost is from the capital and operating expenses of the conversion plants, with less than $1 \%$ coming from the transportation costs. The feedstock, corn stover, is assumed to be obtained for free because corn stover is often left as a waste from corn production, and could be viably used in the proposed operation. The Opex, as

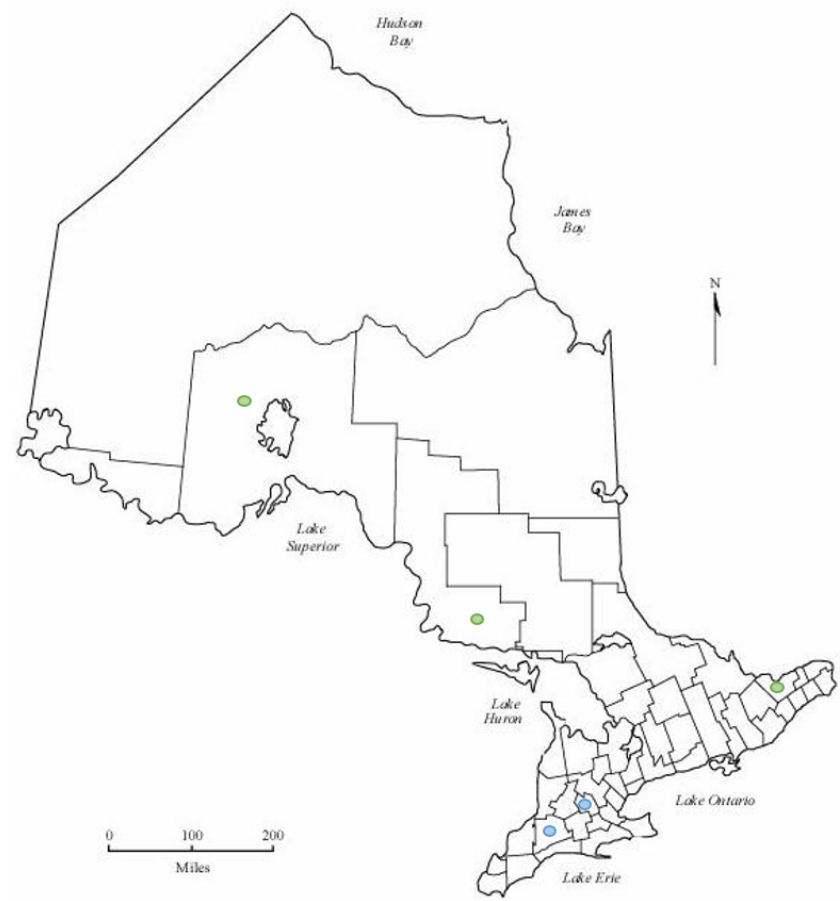

Fig.5. Location of biorefineries for: three most reoccurring plants in green, and the location of the minimum case (two) in blue.

shown in the model data, comes from fuel costs associated with transportation to the fuel production site, which is minimal (about 1\%) compared to the capital expenditure (Capex) or cost of building the facilities and technologies in the biorefinery. As gasification technology is further researched and more commonly used on large scales, the cost of the biorefineries is expected to come down. The total investment for the minimum case is $\$ 42.882$ billion, with 14.8 billion L of fuel produced, more than covering the cost, with a payback period of about 3 years.

The result reported above is for the minimal case, which is the most extreme situation. As the number of sites increases, the cost value of the operation would increase raising the biofuel production cost beyond the estimated \$3 per L. This situation is more likely and would reflect the literature, however, since so many cases were considered, only the lowest cost situation was discussed in detail within the text. This work holds an optimistic view that the future technology of biofuel production will undergo further development that the cost will be lowered with further commercialization. More so, a very aggressive payback period of 3 years realized from the model can be achieved by initiatives such as government incentives and regulations associated with increasing renewable content in liquid fuel, and these policy measures are expected to encourage this technology development.

The above analysis is then repeated with a two-stage stochastic program, using corn production data over the last 5 years. In Figure 6, the results of the biorefinery siting are provided for each case with a specified number of biorefineries. In Figure 7, the two most recurring counties are shown (green) as well as the two minimum gasifier case locations (blue). The two most recurring districts across all the policy decisions are: Ottawa and Peel. In contrast, if the policy decision is set to the minimum of two, the optimal locations to construct the biorefineries are: Brant and Northumberland.

The recommended locations are different due to the stochastic element in the form of corn stover supply, but the cost of the solution for the case with two gasifiers has also risen to $\$ 42.886$ billion from the deterministic solution using the 2016 corn production data, a rise of about $0.01 \%$. To demonstrate the advantage of implementing the stochastic solution rather than basing the solution only on a single scenario, a commonly used metric is the value of the stochastic solution (VSS). The VSS represents the expected benefit gained by the implementation of the stochastic solution as 


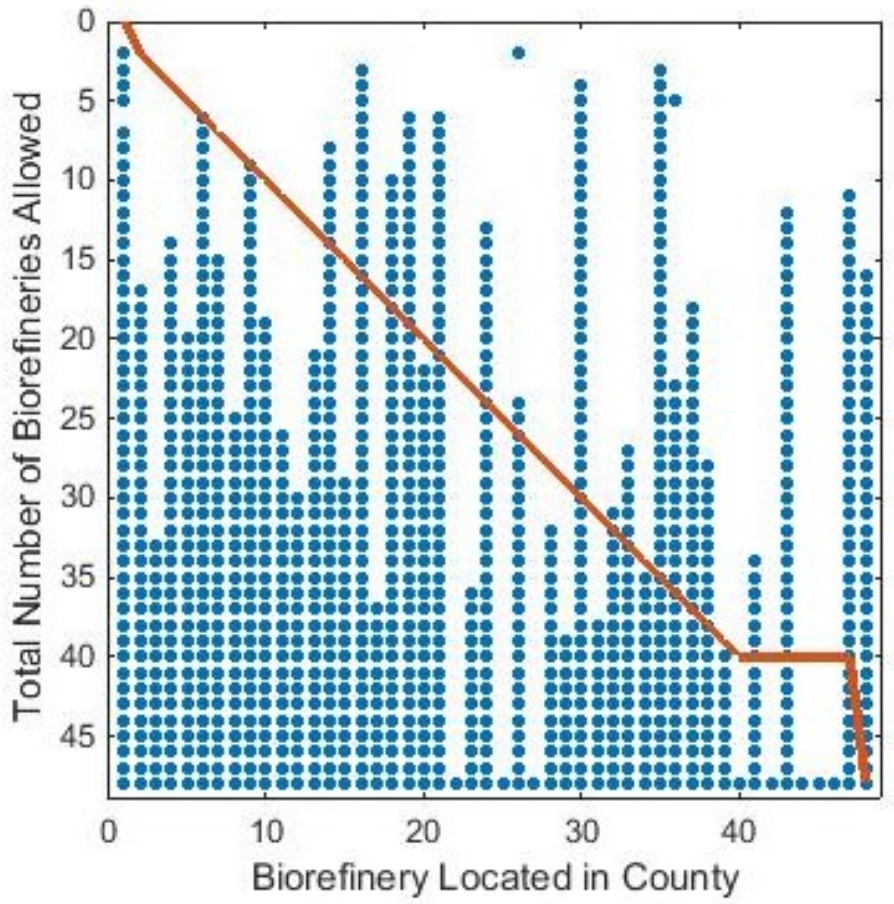

Fig.6. Stochastic biorefinery siting results.

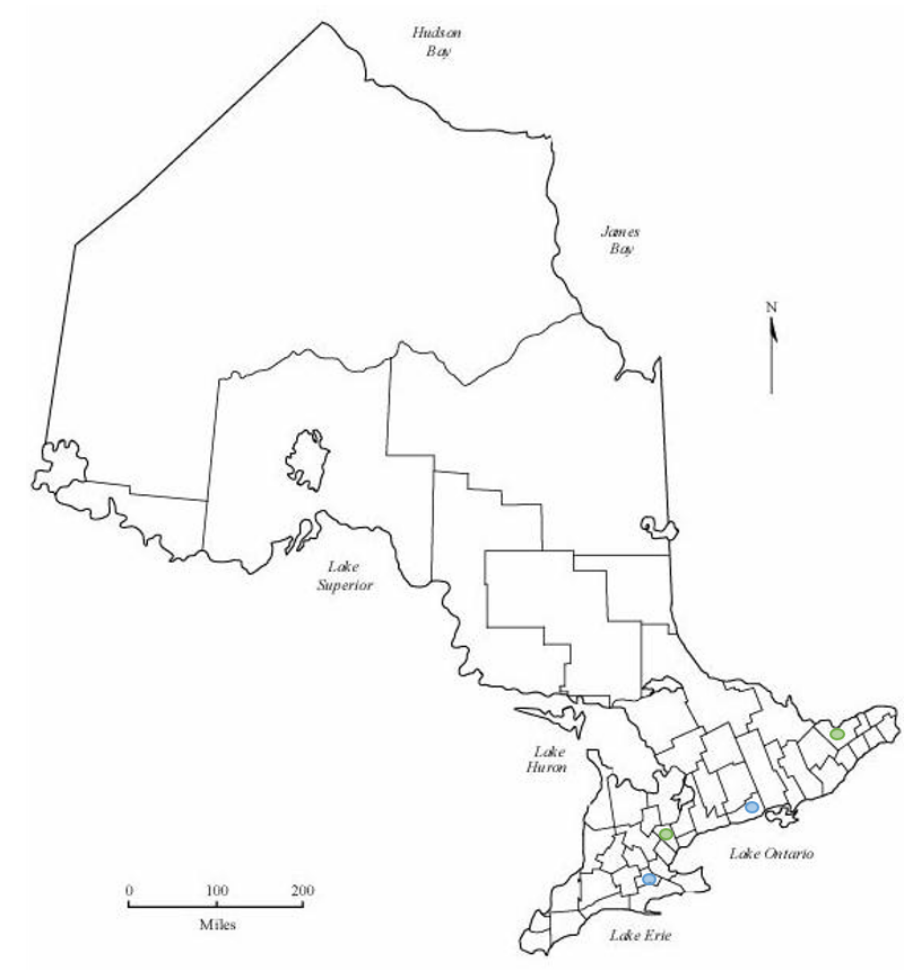

Fig.7. Location of biorefineries for: two most reoccurring plants in green, and the location of the minimum case (two) in blue. compared with the implementation of the deterministic solution using only the 2016 corn harvest data. Figures 8 and 9 show how the expected value of perfect information (EVPI) and VSS vary with the total number of gasification plants allowed, respectively. The plot of EVPI indicates that if the exact biomass supply each year was known, the network could be setup in such a way as to decrease the investment cost by about $\$ 100 \mathrm{~K}-\$ 1 \mathrm{M}$ depending on the policy decision. Figure 9 indicates that there is value in the implementation of the stochastic solution, particularly as the total investment cost only rises by $\$ 4 \mathrm{M}$ as compared with the deterministic solution.

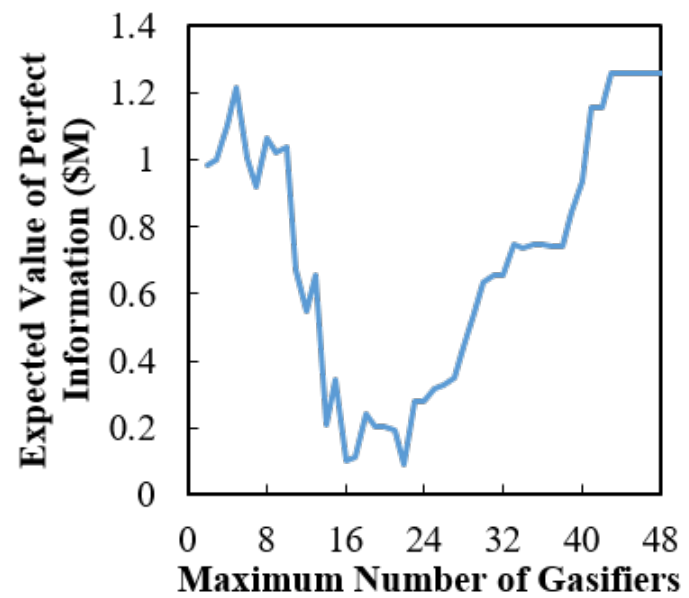

Fig.8. Expected value of perfect information versus maximum number of gasifiers allowed.

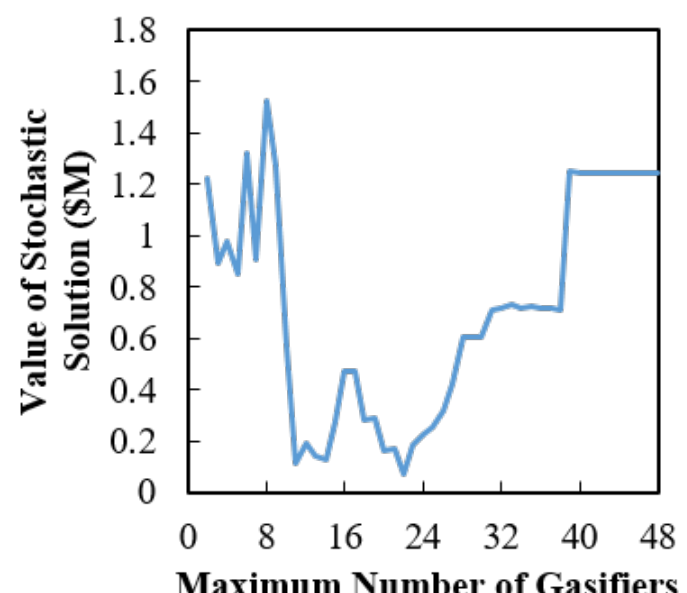

Fig.9. Value of stochastic solution versus maximum number of gasifiers allowed.

\section{Conclusions}

The optimization of a biomass refinery supply chain network in Ontario has been demonstrated using an MILP model in MATLAB. The benefit of incorporating uncertainty of crop supply into the supply chain optimization has also been shown to be beneficial because of high variation in crop yields. The result considering uncertainty is different than the deterministic result, because the availability of corn stover (the stochastic element in this paper) varies significantly across different seasons affecting the optimized 
locations, which is evident by the results from the stochastic solution. The final optimized solution could meet $10 \%$ of the yearly fuel demand of Ontario (14.8 billion liters of fuel) for an investment of $\$ 42.9$ billion, with a payback period of just under 3 years. This costing was arrived at under the assumption that $5 \%$ of the corn production in Ontario was freely available as corn stover, the waste product from corn harvesting. Further, it was demonstrated that the production demand could be met with only two gasification plants of similar capacities to plants currently being examined in the literature. The use of stochastic programming to model uncertainty shows improvement in cost estimates with different availabilities of corn stover supply, and provides a different recommendation of siting locations as the change in number of facilities is set as a policy decision result of the simulation. The present work considers only a single biomass feedstock (i.e., corn stover) and single product (i.e., biodiesel) and future work should consider using a different variety of feedstocks, for example corn stover, wood chips, or energy crops such as switchgrass, as well as multiple products such as ethanol, biodiesel, heat, and electricity.

\section{References}

[1] Acevedo, J., Pistikopoulos, E.N., 1998. Stochastic optimization based algorithms for process synthesis under uncertainty. Comput. Chem. Eng. 22(4-5), 647-671.

[2] AFDC, Alternative Fuels Data Center, 2017. Renewable hydrocarbon biofuels. United States Department of Energy.

[3] Aksoy, B., Cullinan, H., Webster, D., Gue, K., Sukumaran, S., Eden, M., Sammons, N., 2011. Woody biomass and mill waste utilization opportunities in Alabama: transportation cost minimization, optimum facility location, economic feasibility, and impact. Environ. Prog. Sust. Energy. 30(4), 720-732.

[4] Andersen, F.E., Diaz, M.S., Grossmann, I.E., 2013. Multiscale strategic planning model for the design of integrated ethanol and gasoline supply chain. AIChE J. 59(12), 4655-4672.

[5] Andersen, F., Iturmendi, F., Espinosa, S., Diaz, M.S., 2012. Optimal design and planning of biodiesel supply chain with land competition. Comput. Chem. Eng. 47, 170-182.

[6] Anex, R.P., Aden, A., Kazi, F.K., Fortman, J., Swanson, R.M., Wright, M.M., Satrio, J.A., Brown, R.C., Daugaard, D.E., Platon, A., Kothandaraman, G., 2010. Techno-economic comparison of biomass-totransportation fuels via pyrolysis, gasification, and biochemical pathways. Fuel. 89, S29-S35.

[7] Bain, R.L., 1992. Material and energy balances for methanol from biomass using biomass gasifiers. National Renew. Energy Lab(NREL). 136.

[8] Birge, J.R., Louveaux, F., 2011. Introduction to Stochastic Programming. New York, Springer.

[9] CNW, Canada News Wire, 2016. Government of Canada announces panCanadian pricing on carbon pollution.

[10] Čuček, L., Lam, H.L., Klemeš, J.J., Varbanov, P.S., Kravanja, Z., 2010. Synthesis of regional networks for the supply of energy and bioproducts. Clean. Technol. Environ. Policy. 12(6), 635-645.

[11] Demirbas, A., 2001. Biomass resource facilities and biomass conversion processing for fuels and chemicals. Energy Convers. Manage. 42(11), 1357-1378.

[12] Demirbas, A., 2011. Competitive liquid biofuels from biomass. Appl. Energy. 88(1), 17-28

[13] Diwekar, U.M., Rubin, E.S., 1991. Stochastic modeling of chemical processes. Comput. Chem. Eng. 15(2), 105-114.

[14] D'Jesús, P., Boukis, N., Kraushaar-Czarnetzki, B., Dinjus, E., 2006. Gasification of corn and clover grass in supercritical water. Fuel. 85(78), 1032-1038

[15] Dutta, A., Phillips, S.D., 2009. Thermochemical ethanol via direct gasification and mixed alcohol synthesis of lignocellulosic biomass. National Renew. Energy Lab(NREL). 144

[16] Ebadian, M., 2015. Demonstration of corn stover harvest in Canada's outdoor farm show. BioFuelNet Canada.

[17] FAO, Food and Agriculture Organization of the United Nations, 1986. Gasification Fuels

[18] Focus on Geography Series; Province of Ontario, 2011. Canada Statistics.
[19] Gebreslassie, B.H., Yao, Y., You, F., 2012. Design under uncertainty of hydrocarbon biorefinery supply chains: multiobjective stochastic programming models, decomposition algorithm, and a comparison between CVaR and downside risk. AIChE J. 58(7), 2155-2179.

[20] Google Maps APIs.

[21] Grisi, E.F., Yusta, J.M., Khodr, H.M., 2011. A short-term scheduling for the optimal operation of Biorefineries. Energy Convers. Manag. 52(1), 447-456.

[22] Hillier, F.S., Lieberman, G.J., 2000. Introduction to Operations Research. Boston, MA: McGraw-Hill, Inc.

[23] Kim, J., Realff, M.J., Lee, J.H., 2011. Optimal design and global sensitivity analysis of biomass supply chain networks for biofuels under uncertainty. Comput. Chem. Eng. 35(9), 1738-1751.

[24] Kim, J., Realff, M.J., Lee, J.H., Whittaker, C., Furtner, L., 2011. Design of biomass processing network for biofuel production using an MILP model. Biomass Bioenergy. 35(2), 853-871.

[25] Larson, E.D., Jin, H., Celik, F.E., 2009. Large-scale gasificationbased coproduction of fuels and electricity from switchgrass Eric. Biofuels, Bioprod. Biorefin. 3(2), 174-194.

[26] Leibbrandt, N.H., Knoetze, J.H., Görgens, J.F., 2011. Comparing biological and thermochemical processing of sugarcane bagasse: an energy balance perspective. Biomass Bioenergy. 35(5), 2117-2126.

[27] Marie-Andrée, H., Dorff, E., 2015. Corn: Canada's third most valuable crop. Statistics Canada

[28] McLean, K., Li, X., 2013. Robust Scenario Formulations for Strate gic Supply Chain Optimization under Uncertainty. Ind. Eng. Chem. Res. 52(16), 5721-5734.

[29] McLean, K., Ogbe, E., Li, X., 2015. Novel formulation and efficien solution strategy for strategic optimization of an industrial chemical supply chain under demand uncertainty. Can. J. Chem. Eng. 93, 971985.

[30] Mochizuki, T., Chen, S.Y., Toba, M., Yoshimura, Y. 2014. Deoxygenation of guaiacol and woody tar over reduced catalysts. Appl. Catal. B. 146, 237-243.

[31] Natural Resources Canada, 2016. Bioenergy from biomass.

[32] NEB, National Energy Board (NEB), 2016. Canada's Energy Future, 2016. Energy supply and demand projections to 2040.

[33] NETL, National Energy Technology Laboratory. Advantages and efficiency of gasification.

[34] Ogbe, E., Li, X., 2017. A new cross decomposition method for stochastic mixed-integer linear programming. Eur. J. Oper. Res. 256(2), 487-499.

[35] Provincial Field Crop Production and Prices, 2017. Ontario ministry of agriculture, food and rural affairs

[36] Pham, V., El-Halwagi, M., 2012. Process synthesis and optimization of biorefinery configurations. AIChE J. 58(4), 1212-1221.

[37] Rezaiyan, J., Cheremisinoff, N.P., 2005. Gasification technologies: a primer for engineers and scientists. CRC Press.

[38] Sammons, N.E., Yuan, W., Eden, M.R., Aksoy, B., Cullinan, H.T. 2008. Optimal biorefinery product allocation by combining process and economic modeling. Chem. Eng. Res. Des. 86(7), 800-808.

[39] Simchi-Levi, D., Kaminsky, P., Simchi-Levi, E., 1999. Managing the Supply Chains: Concepts, Strategies and Cases. New York, McGrawHill, Inc.

[40] Solomon, S., Qin, D., Manning, M., Chen, Z., Marquis, M., Averyt, K., Tignor, M.M.H.L., Miller, H., 2007. The physical science basis.

[41] Swanson, R.M., Platon, A., Satrio, J.A., Brown, R.C., 2010. Technoeconomic analysis of biomass-to-liquids production based on gasification. Fuel. 89, S11-S19.

[42] Tijmensen, M.J., Faaij, A.P., Hamelinck, C.N., van Hardeveld, M.R. 2002. Exploration of the possibilities for production of Fischer Tropsch liquids and power via biomass gasification. Biomass Bioenergy. 23(2), 129-152.

[43] USEIA, United States Energy Information Administration, 2017a. Oil and the environment.

[44] USEIA, United States Energy Information Administration, 2017b. Biomass renewable energy from plants and animals.

[45] Van Bibber, L., Shuster, E., Haslbeck, J., Rutkowski, M., Olsen, S., Kramer, S., 2007. Baseline technical and economic assessment of a 
commercial scale fischer-tropsch liquids facility. US Dept. Energy. Rep.

[46] Wan, S., Wang, Y., 2014. A review on ex situ catalytic fast pyrolysis of biomass. Front. Chem. Sci. Eng. 8(3), 280-294.

[47] Zamboni, A., Bezzo, F., Shah, N., 2009. Spatially explicit static model for the strategic design of future bioethanol production systems. 2. multiobjective environmental optimization. Energy Fuels. 23(10), 5134-5143.
[48] Zhou, C.H., Xia, X., Lin, C.X., Tong, D.S., Beltramini, J., 2011. Catalytic conversion of lignocellulosic biomass to fine chemicals and fuels. Chem. Soc. Rev. 40(11), 5588-5617.

[49] Yue, D., You, F., Snyder, S.W., 2014. Biomass-to-bioenergy and biofuel supply chain optimization: overview, key issues and challenges. Comput. Chem. Eng. 66, 36-56. 